\title{
A Conversation Analytic Study of Question Design in Mandarin Chinese
}

\author{
LI Feng, ZHAO Jing \\ Shanxi University, Taiyuan, China
}

\begin{abstract}
Questions are pervasive in ordinary conversation as well as in institutional interaction. Based on a corpus of 721 questions in Mandarin Chinese conversation, this article firstly reviews previous studies on questions at home and abroad and gives a brief definition of questions in Conversation Analysis, then expounds the linguistic formats of questions in Mandarin Chinese, and lastly explores the social actions implemented by these questions in Mandarin Chinese conversation.
\end{abstract}

Keywords: Conversation Analysis, question design, linguistic format, social action

Questions have always been a core topic in Chinese and foreign language studies. Language philosophers contrast interrogative sentences with declarative sentences to explore the correspondence between language and the world and study such issues as presupposition, information structure, and speech acts. The ethnographers of speaking point out that many human activities contain questions and answers, and some activities even consist entirely of questions and answers (Hymes, 1962). In the field of grammar study, question (interrogative) is regarded as a type of sentence and the carrier of intonation, grammar, and function combination. Scholars use the transformation to study declaratives and questions within the syntactic mechanism (Quirk, Greenbaum, Leech, \& Svartvik, 1972; Greenbaum, 1996). Scholars in pragmatics explicate that question/questioning can be regarded as a speech act or an indirect speech act, which is used to perform information seeking, requesting, offering help, etc. (Austin, 1962; Searle, 1969). Although pragmatic researches begin to focus on the actions performed by speech, they are still confined to the utterance itself and fail to recognize that sequence position is the key feature of action attribution. According to conversation analysts, any component of turn construction unit (TCU) must be placed within the turn, which is then placed in the sequence, so as to reveal the social action performed by the turn (Schegloff, 2007).

The research on questions in Mandarin Chinese mainly focuses on the four levels of grammar, semantics, pragmatics, and cognition, most of which are the classification of sentence types and the description and summary of sentence functions (see Zhu, 1982; Lin, 1985; Lv, 1990; Xing, 1996; Shao, 1996, etc.); most of these descriptions and summaries are based on corpus divorced from real communicative situations, lacking objective basis and unable to truly reflect the actual situation of Chinese verbal interaction. Therefore, how to rely on real verbal communication activities and how to study specific conversational practices used by

Fund Program: This article was funded by the program of Youth Fund for Humanities and Social Sciences Research, Ministry of Education titled “A Conversation Analytic Study of Question-Response Sequence in Mandarin Chinese” (18YJCZH075).

LI Feng, Associate Professor, School of Foreign Languages, Shanxi University, Taiyuan, China.

ZHAO Jing, MA, School of Foreign Languages, Shanxi University, Taiyuan, China. 
participants in specific sequence positions to perform various social actions are the current research trends (Fox \& Thompson, 2010). Although a few scholars begin to pay attention to the role of questions in institutional discourses such as classroom, court, and media (Huang, 1998; Liao, 2002; Zhao, 2017, etc.), few researches have been carried out from the perspective of Conversation Analysis, and even fewer studies have been conducted on the questions in daily conversation. This field needs to be further studied and it is necessary to take Mandarin Chinese as the research object, discover the question practices in Chinese language communication, and reveal the communication mode of Chinese language under the background of Chinese culture.

\section{Definition of Questions in Conversation Analysis}

Conversation Analysis originates from ethnomethodology, which is a sociological research method that emerged in the United States in the 1960s. The research aim of Conversation Analysis is to discover the conversational practices and characteristics of social action implemented by communicators in the sequential organization of talk-in-interaction. Conversation analysts use an "emic" perspective to analyze corpus, which decomposes language and social interaction from the perspective of "insiders", that is to say, to study communication phenomena from the perspective of communicators themselves. Through the detailed study of corpus, the analyst explores why a particular social action appears in a particular position in a particular way at a particular moment. Also, the specific conversational practices are concluded, and the analysis of deviant cases will further verify the conversational practices through the analysis of corpus one by one.

According to the researches on questions, it is generally possible to judge whether an utterance performs the action of questioning from three aspects, namely, the asymmetry of grammar, intonation, and epistemic. From the perspective of grammar, we habitually discuss questioning in relation to the question per se, but actually not all of questioning is proposed through questions and there are many other syntactic forms which can perform the action of questioning, such as declaratives. It depends on the nature of the information contained in the declarative sentence to determine whether the interrogative action is carried out or not. If the questioner does not possess the information expressed in the declarative sentence, but the recipient does or may possess the information, the declarative sentence is deemed to be performing the act of asking the question, and the recipient is supposed to respond accordingly. In terms of intonation, although we tend to think that all questions are accompanied with a rising intonation, in fact, not all questions are designed with a rising intonation, and not all sentences with rising intonation are questions. Therefore, neither grammar nor intonation alone can be a reliable criterion for judging a questioning action. From the perspective of epistemics, when the declarative sentence made by the speaker belongs to the knowledge domain of the recipient, he/she is seeking confirmation or denial, that is, asking questions. On the contrary, when the information expressed in a declarative sentence belongs to the domain of the speaker's knowledge, the sentence is not actually asking questions although it is formally a question.

\section{The Linguistic Formats of Questions in Mandarin Chinese}

Based on Zhu Dexi (1982), Lin Yuwen (1985), etc., questions are divided into three categories according to their structural and formal characteristics, viz., polar questions, Q-word questions, and alternative questions. In this study, we find that this classification has something in common with the interrogative forms in other languages and polar questions are the most important forms of interrogative questions. 


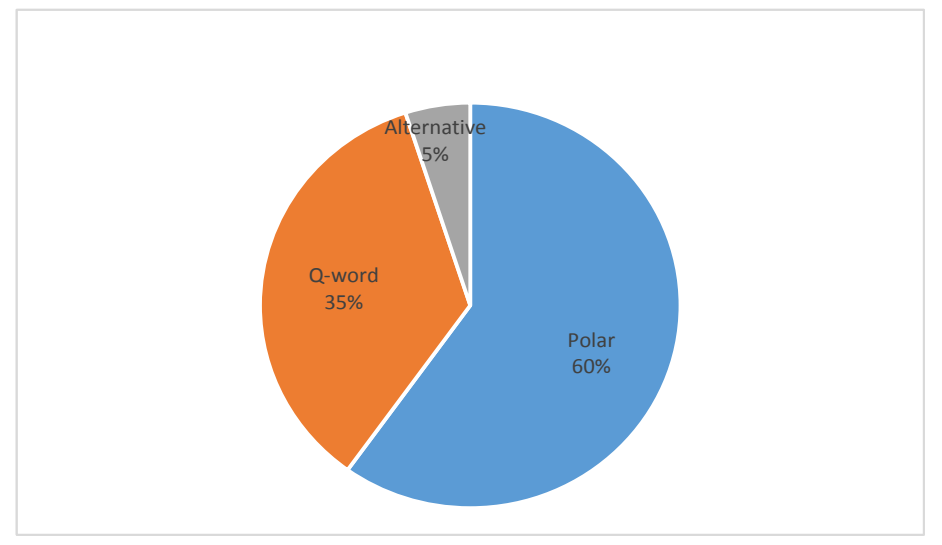

Figure 1. Distribution of question types.

The pie chart above provides a distribution of question types and shows a significant proportion of these question types. It can be seen from Figure 1 that, among the three types of questions mentioned above, polarity questions account for $60 \%$, which is the main practice of asking questions across question types $(\mathrm{n}=721)$. 35\% of all question types are Q-word questions or content questions $(n=253)$, while alternative questions account for $5 \%(n=36)$. The data collected in the present study suggest that polar question type is most widely used by participants in Mandarin Chinese conversation, and the following section will expound the internal structures of polar questions, Q-word questions, and alternative questions.

\section{Polar Questions}

There are many grammatical forms of polar questions. In Mandarin Chinese, the answers to polar questions are affirmative or negative. Declarative, interrogative, tag questions and V-not-V questions constitute the main subtypes of polar questions. Declarative questions are converted from rising or falling declarative sentences and are generally regarded as the most common and neutral polar questions. The interrogative form of a declarative sentence usually ends with a final particle. The $\mathrm{V}$-not-V questions require a yes or no answer. Tag questions express "maximization orientation", thus forcing a particular answer to be consistent with the question to a greater extent (Quirk, Greenbaum, Leech, \& Svartvik, 1985). In spontaneous interaction, declarative sentences are the dominant question types in Mandarin Chinese, as shown in Table 1. This distribution shows the proportion of subtypes of polar questions.

Table 1

\section{Sub-type Distribution of Polar Questions}

\begin{tabular}{ll}
\hline Polar question type & Percent \\
\hline Declarative & $42 \%(\mathrm{n}=181)$ \\
Interrogative & $30 \%(\mathrm{n}=130)$ \\
Tag & $11 \%(\mathrm{n}=48)$ \\
V-not-V & $17 \%(\mathrm{n}=73)$ \\
Total & $100 \%(\mathrm{n}=432)$ \\
\hline
\end{tabular}

Declarative questions. Interrogative questions can be realized in other forms than interrogative sentences. For example, declarative questions take many forms. Some of them achieve their questioning effect with a rising intonation, and others by declaring an event that falls into the recipient's knowledge domain (B-event statement)—something that the recipient has the right to know about the speaker (Labov \& Fanshel, 1977). 
Interrogative questions. As is shown in Table 1, interrogative sentences account for one third of all polar questions and are usually utilized to ask someone to answer yes or no. They basically possess the same form with declarative sentences, but the intonation should be changed into rising tone, or interrogative words added to the end of the sentence. The frequently used interrogative particles in Mandarin Chinese include “吗” (ma), “吧” (ba), and “啊” (a).

Tag questions. Like tag questions in English, tag questions in Mandarin Chinese also have a preference for structural design, which is strongly expected to be consistent with the statement to which the tag question is appended. A tag question in Mandarin Chinese usually takes the format of "declarative + tag question”, which has three properties: (a) It must be attached to a declarative sentence; (b) it is composed of an interrogative construction X not X or an interrogative word like “吧” (Ba), “吗” (Ma), “么” (Me), etc.; and (c) the answer to a tag question must be either a simple positive or negative one. In Chinese, tag questions are frequently used to invite the recipient to answer or confirm the content in the declarative sentence. At the same time, the present speaker signals that his/her turn may be over, and passes the floor to the recipient to take.

V-not-V questions. The V-not- $V$ question is one of the polar questions in Mandarin Chinese. In the formation of $\mathrm{V}$-not- $\mathrm{V}$ questions, the general rule is to put positive and negative sentences together. $\mathrm{V}$-not- $\mathrm{V}$ questions offer a choice between a positive predicate and a negative predicate, which is answered by repeating a positive or negative predicate, rather than a yes/no answer.

\section{Q-Word Questions}

Q-word questions or Wh-questions can be expressed in interrogative words such as "who", "what", "when”, "where”, “why”, etc. They can be related to a person, an object, a time, a place, a reason, etc. Through the analysis of 253 examples, this paper studies the Q-word questions in Mandarin Chinese spontaneous conversations. The following table summarizes the most commonly used question words in Mandarin Chinese.

Table 2

Question Words in Chinese

\begin{tabular}{|l|l|}
\hline 什么/啥 (what) & 为啥/为什么 (why) \\
\hline 哪/哪里 (where) & 多钱 (how much) \\
\hline 多少 (how many) & 多久 (how long) \\
\hline 几 (how many) & 几点 (what time) \\
\hline 谁 (who) & 怎么 (how) \\
\hline 咋 (how) & 哪个/哪些 (which one/ones) \\
\hline
\end{tabular}

\section{Alternative Questions}

Unlike polar questions that require a yes or no answer, alternative questions offer an alternative to two or more statements and ask the recipient to choose the question or one of the alternatives presented in such a question. The formation of an alternative question is the combination of two components by the conjunction “还是” (or). In addition, the words, phrases, and clauses that are linked are likely to have similar categories, attributes, or behaviors. In some cases, the latter option may not appear, but allows the recipient to make an open choice. Shao Jingmin (1996) elaborates the relationship between coordinating components, which can be comparative, alternative, and compatible. According to Quirk et al. (1972, p. 399), the alternative question "contains a separate nucleus for each alternative: a rise occurs on each item in the list, except the last, on which there is a fall, indicating that the list is complete". 


\section{Social Actions Performed by Questions in Mandarin Chinese Conversation}

Social action is the core in human interaction. In talk-in-interaction, all the turn construction units we use may be performing some kind of social action, and the recipient also understands our turn construction units from the perspective of social action. Social action is an unavoidable content in the conversation (Schegloff, 1995). The study of Conversation Analysis is the interpretation of the methods used by participants to perform social actions (methodic account of action) and the analysis of the sequence structure of social actions (Heritage, 1988).

In the present corpus, there are a total of 721 question instances, among which information seeking is considered as the most prominent social action implemented through questions, accounting for $54 \%$. Out of 144 instances being used to initiate repair, 55\% are polar questions and 45\% are Q-word questions. The third type of social action that stands out is confirmation requests, which accounts for $18 \%$ of the whole instances. In addition to seeking information, initiating other repair, and requesting confirmation, questions can be mobilized to perform such actions as requests, offers, proposals, etc., which accounts for a total of $8 \%$ of all questions.

Table 3

Distribution of Social Actions Being Implemented by Question Types

\begin{tabular}{lllll}
\hline Social actions & Polar & Q-word & Alternative & Total \\
\hline Information seeking & $49 \%(\mathrm{n}=190)$ & $48 \%(\mathrm{n}=187)$ & $3 \%(\mathrm{n}=12)$ & $54 \%(\mathrm{n}=389)$ \\
Other-initiated repair & $55 \%(\mathrm{n}=79)$ & $45 \%(\mathrm{n}=65)$ & 0 & $20 \%(\mathrm{n}=144)$ \\
Confirmation request & $100 \%(\mathrm{n}=130)$ & 0 & 0 & $18 \%(\mathrm{n}=130)$ \\
Request/offer/proposal etc. & $100 \%(\mathrm{n}=58)$ & 0 & 0 & $8 \%(\mathrm{n}=58)$ \\
Total & $63 \%(\mathrm{n}=457)$ & $35 \%(\mathrm{n}=252)$ & $2 \%(\mathrm{n}=12)$ & $100 \%(\mathrm{n}=721)$ \\
\hline
\end{tabular}

\section{Seeking Information}

Epistemic asymmetry between participants in interaction is a major factor that drives the use of questions (Stivers, 2010). Traditionally, Q-word questions are characterized by interrogative words in almost all languages. Heritage (2008; 2010) argues that these questions convey different epistemic positions. For example, “whom did you say that to?” means that the speaker knows little or nothing about the person being questioned; "You talked to Steve?" indicates that the speaker is inclined to answer "yes"; "You were talking to Steve, weren't you?" shows that the speaker believes that this is the case and is only seeking confirmation (Pomerantz, 1988; Raymond, 2010; Heritage \& Raymond, 2012). Therefore, these questions imply different epistemic gradients between the questioner and the respondent. Information seeking is generally considered to be the main function of questions, and it is also the most frequent action implemented by questions in the current data. As the data shows, the proportion of information seeking implemented by questions is 54\%. Among the three subtypes of questions, the proportion of polar questions is basically the same as that of Q-word question, and alternative questions constitute the least with only $3 \%$.

\section{Initiating Repair}

When people talk together, the repair mechanism occurs to solve problems of listening, speaking, or understanding in the interaction, among which question is the most easily recognized language resource to initiate the repair. The particular problem to which questions are addressed is called trouble-source. Repair, therefore, refers to an organized set of practices by which conversation participants can solve and potentially solve problems such as speaking, listening, or understanding. There is a range of different formats for 
other-initiation of repair. They vary along a continuum from "weaker" to "stronger" (Schegloff, Jefferson, \& Sacks, 1977). The open-class initiators, such as “啥?” (what) and “啊?” (well), indicate that the recipient has found some trouble in the prior talk, but does not locate any particular repair component within the prior talk. Category-specific interrogatives, such as “谁” (who), “哪儿” (where), and “啥时候” (when) are more specific in that they claim a grasp of the trouble-source as referring to either a person, place, time formulation or object. Repeats of the trouble-source claim the capacity to reproduce it, but not to understand what is meant by it. Candidate understanding claims to hear and have a possible grasp on what is meant, subject to checking this out with the speaker of the trouble-source turn (Sidnell \& Stivers, 2013). As shown in Table 1, other repair initiation takes the second highest proportion of the social actions achieved by questions and the total number in the data is 144 with $20 \%$.

\section{Requesting Confirmation}

Polar questions, especially tag questions, are frequently employed to request confirmation. These questions account for nearly a fifth of all questions, with 130 questions in the data. Knowledge plays a crucial role in determining whether an action is information seeking or confirmation request (Heritage \& Raymond, 2012). Labov and Fanshel (1977) hold that when a speaker makes a statement about an event that belongs to the recipient's domain of knowledge, its function is a polar question and triggers confirmation or non-confirmation. More generally, Stivers and Rossano (2010) argue that it is recipient-tilted epistemic asymmetry that contributes to hearing an utterance as a question. The tag question with rising intonation makes the speaker doubt his/her own hypothesis and asks the recipient to confirm it. In other words, tag questions with rising tones tend to favor expected answers over neutral ones. They invite the recipient to confirm the speaker's hypothesis. This is supported by the fact that confirmation will be spoken in a mid key, indicating that the answer meets the speaker's expectations, while denial is likely to be spoken in a high key, indicating that the answer is contrary to the speaker's expectations.

\section{Request/Offer/Proposal, Etc.}

Well documented, question is the pervasive tool to implement cross-language requests. Brown and Levinson (1978) argue that the format of a request reflects the social relationship between the requester and the request recipient and the nature of the request itself. Through systematic and detailed analysis of spontaneous interaction, conversation analysts reveal how concepts such as social relations or rights are negotiated and (re)constructed by taking turns (Drew, 2013a). As Drew (2013b) puts it, entitlement to requests is suggested, implied, negotiated, and ultimately constituted through the way in which the participants format their contributions. Offer is another common action that speakers use questions to implement. The question format can be used to index and negotiate the participants' local relevant identities (i.e., active/voluntary offerors versus non-voluntary, recruited offerors) regarding the question. Besides request and offer, questions can also be utilized to implement proposal, criticism, challenge, etc. By designing these actions as questions, participants orient to both positions and its compositions of an utterance (Sidnell \& Stivers, 2013).

\section{Concluding Remarks}

\section{Conversation Analysis is}

directed at describing and explicating the competences which ordinary speakers use and rely on when they engage in intelligible conversational interaction. At its most basic, the objective is to describe the procedures and expectations in 
terms of which speakers produce their own behaviour and interpret the behaviour of others. (Heritage, 1984, p. 241)

As an empirical research method, conversational analysis provides a new theoretical perspective for the study of social interaction. This paper employs the research method of Conversation Analysis to systematically study the question design through careful observation of 721 questions in Mandarin Chinese conversation. Three common question formats are discussed in the present study, viz., polar questions, Q-word questions, and alternative questions. Among the polar questions, there are four frequently used question forms including declarative question, interrogative question, tag question, and V-not-V question. Based on these question formats, the article explores a wide range of social actions that questions are regularly utilized to implement: information seeking, repair initiation, request confirmation, and other social actions such as requesting, offering, proposing, criticizing, challenging, etc. By formatting these actions into questions and designing them in a specific way, participants negotiate and display their epistemic gradients and orientations to social and interactive contingency (Sidnell \& Stivers, 2013). Hence, the study of the question design in Mandarin Chinese conversation is to effectively reveal the communication patterns in Mandarin Chinese.

\section{References}

Austin, J. L. (1962). How to do things with words. Oxford: Oxford University Press.

Brown, P., \& Levinson, S. C. (1978). Politeness: Some universals in language usage. Cambridge: Cambridge University Press.

Drew, P. (2013a). Turn design. In J. Sidnell and T. Stivers (Eds.), The handbook of conversation analysis (pp. 131-149). Chichester: Blackwell Publishing Ltd.

Drew, P. (2013b). Conversation analysis and social action. Journal of Foreign Languages, 36, 2-19.

Fox, B. A., \& Thompson, S. A. (2010). Responses to wh-questions in English conversation. Research on Language and Social Interaction, 43(2), 133-156.

Greenbaum, S. (1996). The Oxford English grammar. Oxford: Oxford University Press.

Heritage, J. (1984). Garfinkel and ethnomethodology. Cambridge: Polity Press.

Heritage, J. (1988). Explanations as accounts: A conversation analytic perspective. In C. Antaki (Ed.), Analysing everyday explanation: A casebook of method (pp. 127-144). Thousand Oaks, California: SAGE Publications.

Heritage, J. (2008). Conversation analysis as social theory. In B. Turnered (Ed.), The new Blackwell companion to social theory (pp. 300-320). Oxford: Blackwell.

Heritage, J. (2010). Conversation analysis: Practices and methods. In D. Silverman (Ed.), Qualitative sociology. (3rd ed.). (pp. 208-230). London: Sage.

Heritage, J., \& Raymond, G. (2012). Navigating epistemic landscapes: Acquiescence, agency and resistance in responses to polar questions. In J.-P. De Ruiter (Ed.), Questions: Formal, functional and interactional perspectives (pp. 179-192). Cambridge: Cambridge University Press.

Huang, G. W. (1998). Question and answer analysis of English advertising title. Foreign Language Teaching, (19), 69-75.

Hymes, D. (1962). The ethnography of speaking. In T. Gladwin and W. C. Sturtevant (Eds.), Anthropology and human behavior (pp. 13-53). Washington DC: Anthropological Society of Washington.

Labov, W., \& Fanshel, D. (1977). Therapeutic discourse: Psychotherapy as conversation. New York: Academic Press.

Liao, M. Z. (2002). The status quo of Chinese courtroom trials from linguistic perspective. Applied Linguistics, (4), 25-36.

Lin, Y. W. (1985). On interrogative questions. Chinese Language, (2), 91-98.

Lv, S. X. (1990). Lv Shuxiang collected works (1st volume). Beijing: Commercial Press.

Pomerantz, A. (1988). Offering a candidate answer: An information seeking strategy. Communication Monographs, (55), 360-373.

Quirk, R., Greenbaum, S., Leech, G., \& Svartvik, J. (1972). A grammar of contemporary English. London: Longman.

Quirk, R., Greenbaum, S., Leech, G., \& Svartvik, J. (1985). A comprehensive grammar of the English language. London: Longman. 
Raymond, G. (2010). Grammar and social relations: Alternative forms of yes/no-type initiating actions in health visitor interactions. In A. F. Freed and S. Ehrlich (Eds.), “Why do you ask?”: The function of questions in institutional discourse (pp. 87-107). New York: Oxford University Press.

Schegloff, E. A. (1995). Discourse as an interactional achievement III: The omnirelevance of action. Research on Language and Social Interaction, 28(3), 185-211.

Schegloff, E. A. (2007). Sequence organization in interaction: A primer in conversation analysis. Vol. 1. Cambridge: Cambridge University Press.

Schegloff, E. A., Jefferson, G., \& Sacks, H. (1977). The preference for self-correction in the organization of repair in conversation. Language, 53(2), 361-382.

Searle, J. R. (1969). Speech acts. Cambridge: Cambridge University Press.

Shao, J. M. (1996). Research on interrogative questions in modern Chinese. Shanghai: East China Normal University Press.

Sidnell, J., \& Stivers, T. (2013). The handbook of conversation analysis. Chichester: Blackwell Publishing Ltd.

Stivers, T. (2010). An overview of the question-response system in American English. Journal of Pragmatics, 42, $2772-2781$.

Stivers, T., \& Rossano, F. (2010). Mobilizing response. Research on Language and Social Interaction, 43, 3-31.

Xing, F. Y. (1996). Chinese grammar. Changchun: Northeast Normal University Press.

Zhao, H. P. (2017). The over-realization analysis of teacher institutional identity in the question-and-answer sequence in graduate English class. Overseas English, (2), 6-7.

Zhu, D. X. (1982). Grammar handout. Beijing: Commercial Press. 